\title{
Effect of Nano Structured NiFe and NiP Thin Layer Coatings on Structural and Mechanical Properties of Mild Steel
}

\author{
R. Kannan, E. Shobhana, K. Arun, S. R. Vijay Balaji
}

\begin{abstract}
The nano crystalline thin coating of NiFe and NiP on the surface of mild steel at bath temperature of $40^{\circ} \mathrm{C}$ has been successfully carried out by using electroplating technique in order to enhance the structural and mechanical properties of mild steel. The NiFe \& NiP thin layers were coated on mild steel at constant current density and $\mathrm{pH}$ over a deposition period of 30 minutes. All the coated mild steel samples were subjected to various characterization techniques like X-ray Diffraction method (XRD), Vickers hardness, surface roughness and wear test to reveal the effect of NiFe and NiP on mild steel. The mechanical properties such as surface roughness and wear behavior were investigated by using Stylus profilometer and Pin on disc method. The coated mild steel exhibits enhanced mechanical properties than that of uncoated mild steel. The variations in structural and mechanical properties of coated mild steel were also studied.
\end{abstract}

Keywords: Current density, NiFe, NiP, XRD, and pin \&disc.

\section{INTRODUCTION}

In the modern industries, the surface enhancement of alloy engineering materials plays an important role to prevent the material from corrosion and service failure. Several methods are available to prevent the parts of modern engineering devices and one of the suitable method is to coat the thin layers of alloy materials on its surface [1-5]. Surface coatings technology is widely acceptable used technique to enhance the structural and mechanical properties of base material. Mild steel plays a significant role for the production of automobile and electrochemical devices due to its admirable mechanical properties like high strength, weldability. Mild steel has extensive applications in the manufacturing industry but still the challenge is to control its corrosion and wear which leads to have an impact on manufacturing process.In order to improve the mechanical properties of mild steel, thin alloy coatings were preferred [6 -9]. In this current research work, two different alloys (NiFe and NiP) have been chosen to coat as a thin layer on mild steel. Generally nickel based thin layers are preferred to enhance the mechanical properties of mild steel [10-12]. The nano crystalline metal alloys like $\mathrm{NiP}$ had a great usage in automotive and aerospace industries. These alloys have been used as a decorative coatings on parts

Revised Version Manuscript Received on 10 September, 2019.

R. Kannan, Department of Science and Humanities - Physics Division, Kumaraguru College of Technology, Coimbatore - 49, Tamilnadu, India.

E. Shobhana, Department of Science and Humanities - Physics Division, Kumaraguru College of Technology, Coimbatore - 49, Tamilnadu, India.

K. Arun, Department of Mechanical Engineering, Kumaraguru College of Technology, Coimbatore - 49, Tamilnadu, India.

S. R. Vijay Balaji, Department of Mechanical Engineering, Kumaraguru College of Technology, Coimbatore - 49, Tamilnadu, India. (Email: kannan.r.sci@kct.ac.in)

of modern engineering tools to prevent the machines from corrosion and wear. In addition to NiP, NiFe is also widely used material for storage device applications [13-17].

There are numerous physical and chemical methods are available to coat the thin layers on mild steel. In the current research work, electrodeposition have been employed for the thin layer coating processes due to its abundant advantages likeeconomic, easy to control film thickness and surface morphology of nanostructures.The main advantage of electroplating technique is the large scale production which is essentially needed aspect for industrial point of view. In the recent days, the investigators show considerable interest on nano layer coatings to enhance the mechanical properties of mild steel. The current research work predominantlyexamine the effect of NiFe and NiP alloy thin films on the structural and mechanical properties of mild steel for automobile and mechanical high strength applications.

\section{EXPERIMENT}

The nano crystalline $\mathrm{NiFe}$ and $\mathrm{NiP}$ alloy thin films are coated on the surface of mild steel at electroplating bath temperature of $40^{\circ} \mathrm{Cover}$ the plating time of 30 minutes through electroplating technique. The electroplating bath conditions like concentration, $\mathrm{pH}$ and temperature are shown in table 1 . The mild steel plate of size $7.5 \mathrm{~cm}$ as length and 1.5 $\mathrm{cm}$ as breadth (dia $0.6 \mathrm{~cm}$ )have been used as a cathode and a pure mild steel of above said size act as an anode.In order to enhance the quality of thin layer coatings, just before the deposition both the substrates were subjected to the sequences of cleaning processes.Initiallythe substrates have been cleaned with help of emery sheets and followed by soap solution andacid (diluted $\mathrm{H}_{2} \mathrm{So}_{4}$ ) cleaning. Finally all the MS samples are washed by using triple distilled water.

All the essential chemicals were dissolved in triple distilled water to make the electroplating bath for $\mathrm{NiFe}$ and $\mathrm{NiP}$ alloy coatings. The polished MS samples were dipped into the prepared electroplating bath. The $\mathrm{pH}$ of the solutionwas kept in at constant as 7 by adding few drops of ammonia solution. The constant current of $75 \mathrm{~mA}$ was allowed to pass through the substrates with help of dual power supply (30 Volts and 1 Amphere). After 30 minutes the MS Sample (cathode) was carefully removed from electroplating bath and washed by distilled water. The $\mathrm{NiFe}$ and NiP coated mild steel was dried for few seconds and 
packed with the help of air lock covers.

To investigate the structural and mechanical properties of $\mathrm{NiFe}$ and NiP coated mild steel, all the coted mild steels were subjected to various characterization methods like SEM (Scanning Electron Microscope), XRD (X-ray diffraction pattern) and wear analysis.

Table 1.Electrodepostion - optimized conditions for NiFe and NiP thin films

\begin{tabular}{|c|c|c|}
\hline S.No & Chemical / Parameter & Data (g/l) \\
\hline 1 & Nickel sulphate & 55 \\
\hline 2 & Ferrous sulphate & 20 \\
\hline 3 & Phosphorus acid & 15 \\
\hline 4 & Tri sodium citrate & 50 \\
\hline 5 & Boric acid & 10 \\
\hline 6 & Temperature & $40{ }^{\circ} \mathrm{C}$ \\
\hline 7 & Current density & $1 \mathrm{~A} / \mathrm{dm}^{2}$ \\
\hline 8 & Deposition time & $30 \mathrm{mins}$ \\
\hline
\end{tabular}

\section{RESULT AND DISCUSSION}

\section{Structural analysis}

\section{SEM Analysis}

The surface investigation of $\mathrm{NiFe}$ and $\mathrm{NiP}$ coated thin film was shown in figure 1. The SEM micrograph reveals that the $\mathrm{NiFe}$ and NiP coated mild steel are bright, uniform, void free and almost crack free. The $\mathrm{Ni}, \mathrm{Fe}$ and $\mathrm{P}$ atoms were uniformly distributed over the surface of mild steel. The mild steel coated with $\mathrm{NiFe}$ exhibit the spherical shaped crystallites and is clearly visible in SEM micro graph.

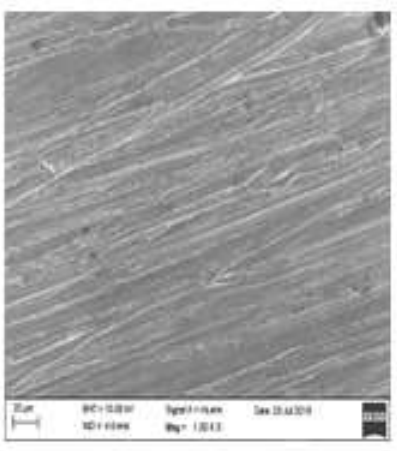

(a)

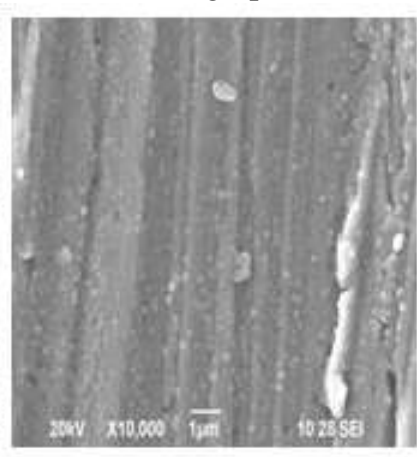

(b)
Figure 1. SEM micrograph of mild steel (a) coated with NiFe (b) coated with $\mathrm{NiP}$

\section{XRD Analysis}

The X-ray diffraction pattern of NiFe and NiP thin layers coated on mild steel surface are shown in figure 2. The XRD result discloses the presence of crystalline phase in $\mathrm{NiFe}$ and $\mathrm{NiP}$ thin films. The obtained XRD data for $\mathrm{NiP}$ and $\mathrm{NiFe}$ were compared with standard JCPDS and found that the crystal structure was cubic. The crystalline size was calculated by usingScherrer formula. From XRD data, it is concluded that the average crystalline size of NiFe layer is around $49 \mathrm{~nm}$ and for NiP layer the crystalline is around 86 nm.

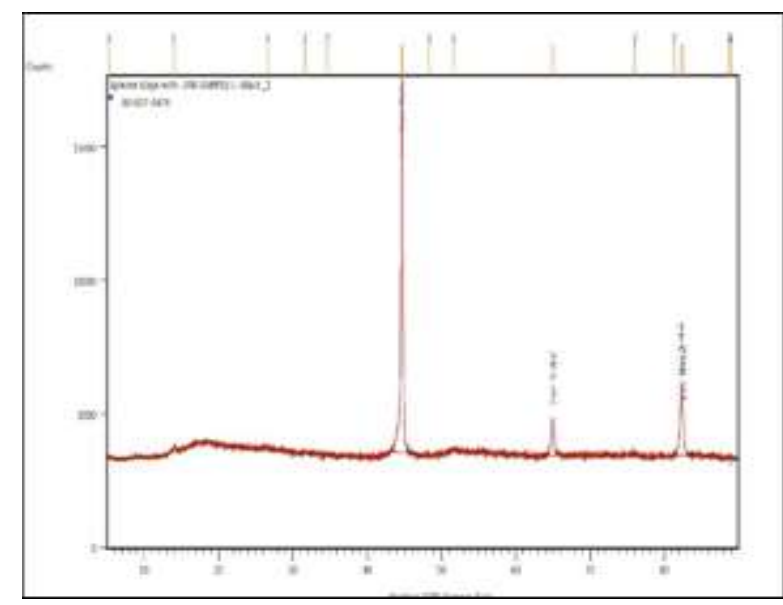

Figure 2. XRD analysis of NiFe coated on mild steel.

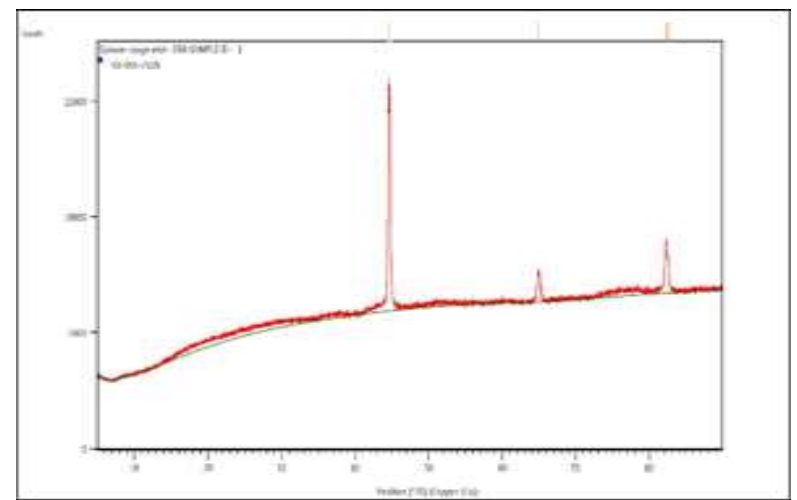

Figure 3. XRD analysis of NiP coated on mild steel.

The presence of sharp peaks in XRD pattern of both $\mathrm{NiFe}$ and NiP thin layers on mild steel reveals the existence of crystalline phase and the crystalline size is in the range of few tens of nano meter which greatly enhances the mechanical properties of mild steel like high hardness, better corrosion resistance and enhanced wear resistance. The d- spacing value in $\mathrm{NiFe}$ and $\mathrm{NiP}$ alloy have been found to be 1.56 and $1.25 \AA$ respectively. The calculated values are listed in table 2.

Table 2. XRD data for NiFe and NiP thin layers on mild steel

\begin{tabular}{|l|c|c|c|c|c|}
\hline Sample & $\begin{array}{c}2 \theta \\
\left(\mathrm{A}^{0}\right)\end{array}$ & $\begin{array}{c}\mathrm{d} \text { - } \\
\text { spacing } \\
\left(\mathrm{A}^{0}\right)\end{array}$ & $\begin{array}{c}\text { Gystallime } \\
\text { size D } \\
\text { nin }\end{array}$ & $\begin{array}{c}\text { Strain } \\
\mathbf{1 0 ^ { - 4 }}\end{array}$ & $\begin{array}{c}\text { Dislocation } \\
\text { density }\left(\mathbf{1 0}^{14}\right. \\
\left./ \mathbf{m}^{2}\right)\end{array}$ \\
\hline $\mathrm{NiFe}$ & 67 & 1.56 & 49 & 7.3590 & 4.1649 \\
\hline $\mathrm{NiP}$ & 76.6 & 1.25 & 86 & 16.8726 & 1.3520 \\
\hline
\end{tabular}

Wear analysis

Wear test is carried out to predict the wear performance and to investigate the surface hardness of the coated material. In engineering application point of view, Wear resistance is a very important parameter. This to evaluate the wear property of the material and then the material is adequate for specific application in various manufacturing industries. This wear

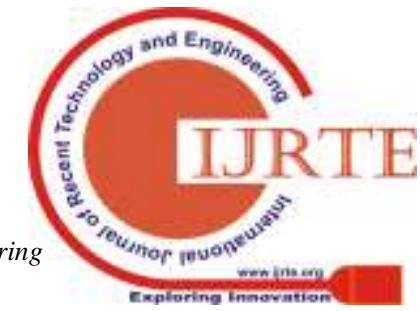


analysis carried out by different methods, in this current research work pin on disc wear testing technique have been employed.In pin on disc technique, the work piece (coated material) travels in unidirectional for an unlimited time at a range of linear velocity. It depends only on position of the pin from the centre of the disc. In this pin and disc technique, 72 HRC hardness steel disc is used and we fix a pin $50 \mathrm{~mm}$ distance from the centre of the disc. So, the pin travels 314 $\mathrm{mm}$ in one revolutions. This test is carried out at room temperature under zero lubricated conditions. From that, we set a parameter for wear test. The parameters are listed below in table 3.

Table 3. Pin and Disc parameter details

\begin{tabular}{|c|c|}
\hline Name of parameters & Data \\
\hline Pin material & Sample1: Mild steel \\
\cline { 2 - 2 } & $\begin{array}{c}\text { Sample2: NiFe coated } \\
\text { mild steel }\left(40^{\circ} \mathrm{C}\right)\end{array}$ \\
\cline { 2 - 2 } & $\begin{array}{c}\text { Sample3: NiP coated mild } \\
\text { steel }\left(40^{\circ} \mathrm{C}\right)\end{array}$ \\
\hline Disc material & EN 31 steel \\
\hline Pin dimension & $\begin{array}{c}\text { Rectangular specimen } \\
\text { with } 49 \mathrm{~mm} \text { length, } 6 \mathrm{~mm} \\
\text { breadth and } 6 \mathrm{~mm} \text { width }\end{array}$ \\
\hline Sliding velocity & $1.7 \mathrm{~m} / \mathrm{s}$ \\
\hline Sliding speed & $300 \mathrm{rpm}$ \\
\hline Load & $20 \mathrm{~N}$ \\
\hline Sliding distance & $1000 \mathrm{~m}$ \\
\hline Sliding time & 10 min $(600 \mathrm{~seconds})$ \\
\hline
\end{tabular}

The wear test results are obtained after a time period of 10 minutes (time taken for wear test). Wear, coefficient of friction, frictional force are recorded during the test against the time.The results are shown in the following figure drawn between wear vs time, coefficient of friction vs time and Frictional Force vs time for uncoated MS sample (figure 3).

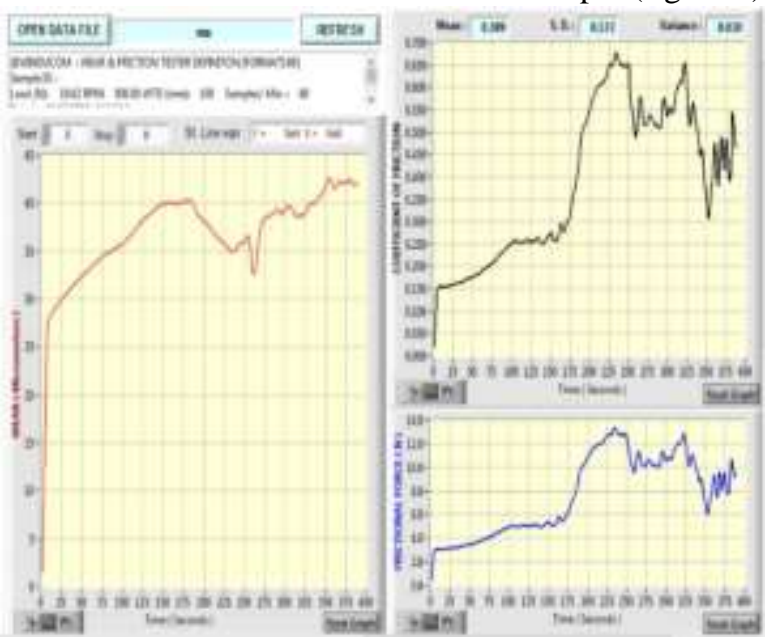

Figure 3: Wear analysis of uncoated mild steel.

The graph of wear (micrometre) and time (seconds) shows that steep increase in wear upto 28 micron in about 10 seconds and later on it increases gradually upto 40 microns in next 150 seconds. The co-efficient of friction is about 0.15 and the fictional force is about $3 \mathrm{~N}$ for uncoated MS sample.

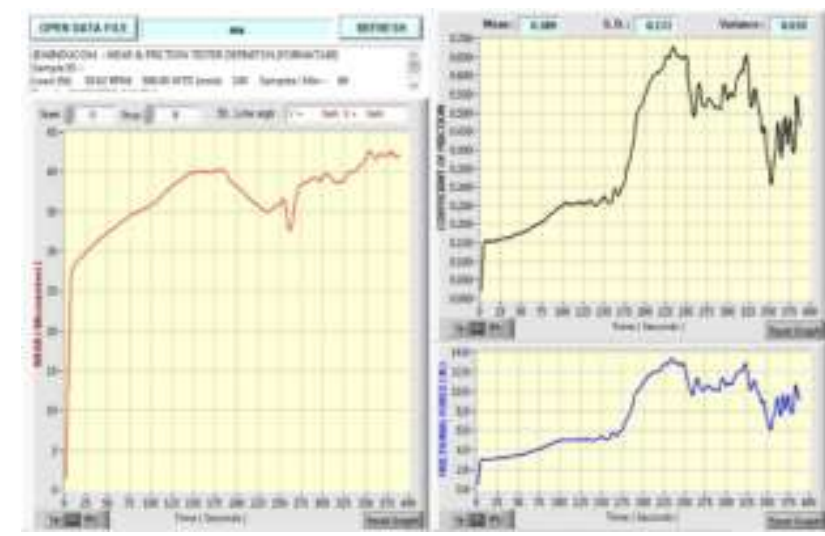

Figure 4: Wear analysis of NiP coated mild steel.

The wear test graph on MS rod coated with NiP shows that steep increase in wear upto 20micron (figure 4)which is less than that of uncoated MS and later it increases gradually upto 55 microns in next 600 seconds. The Co-Efficient of friction is about 0.5 which is greater than uncoated MS and the fictional force is about $10 \mathrm{~N}$ which is $7 \mathrm{~N}$ greater than the uncoated MS.

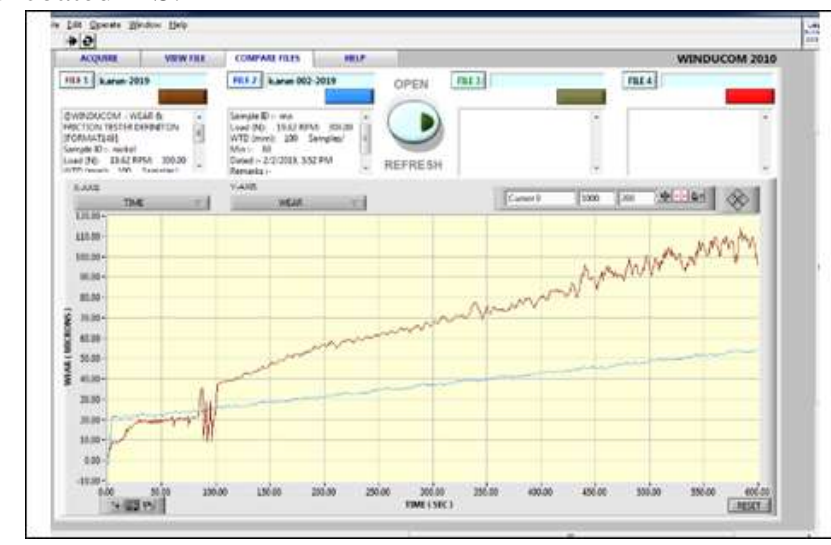

Figure 5: Wear analysis of NiFe coated mild steel.

The Wear test graph of NiFe coated on MS rod shows that steep increase in wear upto 20 micron which is lesser than that of uncoated MS and later it increases gradually upto 110 microns with greater fluctuation in next 600 seconds. The Co-Efficient of Friction is about 0.3 which is greater than uncoated MS and the fictional force is about $6 \mathrm{~N}$ which is $3 \mathrm{~N}$ greater than the uncoated MS (figure 5).

From figure 6, when comparing the Wear resistance characterises of $\mathrm{NiFe}$ and $\mathrm{NiP}, \mathrm{NiP}$ coated mild steel has better wear resistance compared with $\mathrm{NiFe}$. NiP shows 10 microns wear at $\mathrm{x}$ seconds whereas NiFe shows 20 microns of wear at the same $\mathrm{x}$ seconds 


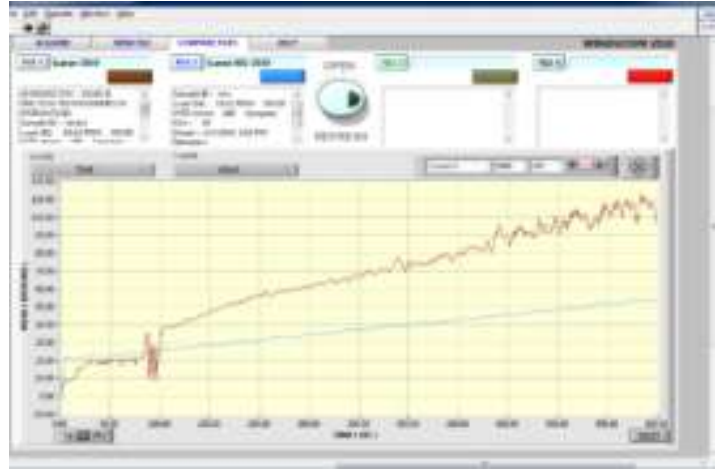

Figure 6. Comparison of Wear between NiFe (Blue) and NiP (Brown) coated mild steel

From the graph 7, When comparing the frictional force of $\mathrm{NiFe}$ coated on MS and NiP coated on MS, NiP coated on MS has greater frictional force about $11 \mathrm{~N}$ when compared to $\mathrm{NiFe}$ coated on MS. NiFe coated on MS shows $5 \mathrm{~N}$ of frictional force at $\mathrm{x}$ seconds whereas NiP coated on MS show $11 \mathrm{~N}$ of frictional force at $\mathrm{x}$ seconds After that both the coating show fluctuation in fictional force after a period of time both approximately shows about $11 \mathrm{~N}$ of fictional force.

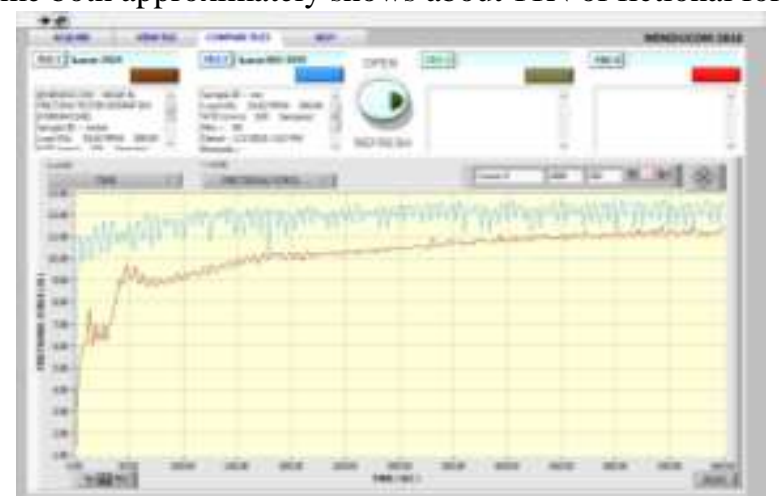

Figure 7. Comparison of frictional force between $\mathrm{NiFe}$ (Blue) and NiP (Brown) coated mild steel

From the graph 8, When comparing co-efficient of friction of $\mathrm{NiFe}$ coated on MS and NiP coated on MS, NiP coated on MS has greater co-efficient of friction about 0.55 when compared to NiFe coated on MS . NiFe coated on MS shows 0.3 of co-efficient of friction at $\mathrm{x}$ seconds whereas NiP coated on MS show 0.55 of co-efficient of friction at $\mathrm{x}$ seconds and after that both the coating show fluctuation in co-efficient of friction after a period of time both approximately shows about 0.55 of co-efficient of friction at 600 th secondThe final wear loss value of MS sample is around $40 \mu \mathrm{m}$ which is decreased to $20 \mu \mathrm{m}$ for $\mathrm{NiP}$ thin layer.From the table 3 , the wear rate of the uncoated mild steel is high and the NiP coated mild steel exhibit lower wear rate. Thus, it is evidenced that the wear resistance of NiP coated mild steel at $40{ }^{\circ} \mathrm{C}$ has the better wear resistance.
Table 4: Wear loss, frictional force and coefficient of friction of MS and NiW coated MS

\begin{tabular}{|c|c|c|c|}
\hline Sample & $\begin{array}{c}\text { Wear loss } \\
(\mathbf{m m})\end{array}$ & $\begin{array}{c}\text { Frictional } \\
\text { force }(\mathrm{N})\end{array}$ & $\begin{array}{c}\text { Coefficient } \\
\text { of friction }\end{array}$ \\
\hline Mild steel & 40 & 3.1 & 0.15 \\
\hline $\begin{array}{c}\text { NiFe coated mild } \\
\text { steel }\left(40^{\circ} \mathrm{C}\right)\end{array}$ & 30 & 6 & 0.3 \\
\hline $\begin{array}{c}\text { NiP coated mild } \\
\text { steel }\left(40^{\circ} \mathrm{C}\right)\end{array}$ & 20 & 10 & 0.5 \\
\hline
\end{tabular}

Surface roughness

The surface roughness value of NiP coated mild steel which exhibit better wear resistance have been analyzed by using stylus profilometer are given below.

Average Roughness(Ra) $\mu \mathrm{m}-0.295$

RMS Roughness (Rq) $\mu \mathrm{m}-0.405$

Mean Roughness Depth (Rz) $\mu \mathrm{m}-2.335$

\section{CONCLUSION}

The nano crystalline $\mathrm{NiFe}$ and $\mathrm{NiP}$ thin layers has been successfully coated on the mild steel surface for high strength applications through electroplating technique. The perceived details are listed below.

* From SEM analysis it is concluded that, the NiFe and $\mathrm{NiP}$ coated mild steel surface are uniform, bright, crack free and void free.

* The XRD pattern of $\mathrm{NiFe}$ and NiP coated mild steel exhibit the nanocrystalline phase and the average crystalline size was calculated as around $86 \mathrm{~nm}$ for $\mathrm{NiP}$ and $43 \mathrm{~nm}$ for $\mathrm{NiFe}$ coatings.

* The wear analysis of coated and uncoated mild steel have been compared by using pin and disc method.

* From the comparison of coated and uncoated MS samples it is seen that the wear of MS rod is reduced when it is coated with NiP alloy.

* Thus the NiP thin layer enhances the surface properties of MS, thus decreasing its wear rate or increasing wear resistance.

* Hence the application of NiP thin layer on MS material improves the failure time of the material due to lower wear rate.

\section{ACKNOWLEDGEMENT}

The authors would like to express their hearty thanks to the Management of Kumaraguru College of Technology, Coimbatore - 49, Tamilnadu, India for providing financial support to carry out this research work.

\section{REFERENCES}

1. Ankita Sharma, Ajay K. Singh. Cent. Eur. J. Eng. • 1(3) • 2011 • 234-243 DOI: 10.2478/s13531-011-0023-8.

2. Mahmud Abdulmalik Abdulrahaman et al 2017 Adv. Nat. Sci: Nanosci. Nanotechnol. 8015016.

3. Kulka M, Mikolajczak D, Makulu N, Dziarski P and Miklaszewski A 2016 Surf. Coat. Tech. 291293.

4. E. Selva kumar, S. Venkateshwaran, R. Kannan, M. Selvambikai \& A. S. Pradeep "An Electrode Position Of Tungsten Coatings On The Mild Steel: Structural And Its 
Wear Behaviour." International Journal of Mechanical and Production Engineering Research and Development, 8, no. 7 (2018): 1012-1018.

5. Venkateshwaran S., Selvakumar E., Senthamil selvan P., Selvambikai M., Kannan R., Pradeep A.S. (2019) Corrosion and Magnetic Characterization of Electroplated NiFe and NiFeW Soft Magnetic Thin Films for MEMS Applications. In: Lakshminarayanan A., Idapalapati S., Vasudevan M. (eds) Advances in Materials and Metallurgy. Lecture Notes in Mechanical Engineering. Springer, Singapore.

6. R Kannan et al 2018 Mater. Res. Express 5046414.

7. Kannan R, Ganesan S, Selvakumari TM (2012) Synthesis and characterization of nanocrystallineNiFeWS thin films in diammonium citrate bath. Digest J Nanomater Biostruct 7(3):1039-1050.

8. R Kannan, S Ganesan, TM Selvakumari "Structural and magnetic properties of electrodeposited Ni-Fe-WS thin films." Optoelectron Adv Mat, 6, no. 3-4, (2012): 383388.

9. Anandhi Meena, B., P. Thiruvalar Selvan, B. Nagaraj, S. Raghavan, S. Suganthi, and V. Karthiyayini. "A novel splitring resonator antennas for biomedical application." J Pure Appl Microbiol 9, no. Special edition (2015): 235-242.

10. O.S. Fayomi, V.R. Tau, A.P.I. Popoola, B.M. Durodola, O.O. Ajayi, C.A. Loto, and O.A. Inegbenebor,. J. of Mat. and Env. Sci., 3, (2011) 271.

11. M. Palaniappa, S.K. Seshadri,Friction and wear behavior of electroless Ni-P and Ni-W-P alloy coatings, Wear, 265 (2008), pp. 735-740.

12. Qin, Liyuan, Jiying Xu, Jianshe Lian, Zhonghao Jiang, and Qing Jiang. "A novel electrodeposited nanostructured Ni coating with grain size gradient distribution." Surface and Coatings Technology 203, no. 1-2 (2008): 142-147.

13. SadanandaRashmiLijuEliasAmparChitharanjan Hegde. "Multilayered Zn-Ni alloy coatings for better corrosion protection of mild steel" Engineering Science and Technology, an International Journal Volume 20, Issue 3, June 2017, Pages 1227-1232.

14. Kato, Koji. "Wear in relation to friction-a review." Wear 241, no. 2 (2000): 151-157.

15. rasad, D.S., Ebenezer, N.S. \& Shoba, C. Trans Indian Inst Met (2017) 2601. https://doi.org/10.1007/s12666-017-1121-y

16. C.S.Ramesh and S.K.Seshadri"Tribological characteristics of nickel based composite coatings, Wear Volume 255, Issues 7-12, August-September 2003, Pages 893-902.https://doi.org/10.1016/S0043-1648(03)00080-2

17. A.P.I.PopoolaaC.A.LotoabC.O.OsifuyeaV.S.Aigbodiona cO.M.Popool. "Corrosion and wear properties of Ni-Sn-P ternary deposits on mild steel via electroless method." Alexandria Engineering Journal, Volume 55, Issue 3, September 2016, Pages 2901-2908

18. K. Hari Krishnan, S. John, K.N. Srinivasan, J. Praveen, M. Ganesan, P.M. Kavimani,An overall aspect of electroless Ni-P depositions - a review article,Metall. Mater. Trans. A, 37 (June) (2006). 